\title{
Mind Theory and the Role of Financial Decision and Process Role of Optogenetics
}

http://doi.org/10.21272/fmir.4(1).40-50.2020

\section{Ana Njegovanović}

Master of Economics, Lecturer at Faculty of Biotechnology in Zagreb; Faculty of Economics and Tourism, University of J. Dobrila in Pula, Croatia

\begin{abstract}
This paper is devoted to the study of functional relationships between behavioural finance, in particular when making decisions in the financial market, and the theory of reason and optogenetics. The purpose of this paper is to analyze the interaction of financial decision-making processes with the key principles of the mental state model (theory of mind) and define the role of optogenetics. The author notes that the use of the theory of reason in behavioural finance allows to consider the key characteristics of the mental state of the subject of economic relations (thoughts, perceptions, desires, intentions, feelings have an internal mentalistic and experimental content). The author notes that decision-making at any level characterizes the complex network of scientific industries that allow us to understand the complexity of financial decision-making and the role and significance of the laws of thermodynamics and entropy. Modelling neural networks (based on the experimental approach), the paper presents the results of research in the context of analyzing behavioural changes in our brain under the following scenarios: at the stage of awareness of certain processes; if we participate (or do not) participate in these processes. The following conclusions are made in the paper: for the normal states of anxiety, the greatest number of possible configurations of interactions between brain networks, which represent the highest values of entropy is characteristic. These results are obtained from the study of a small number of participants in the experiment, but give an objective assessment and understanding of the complexity of the research and the guidance that include a scientific basis in the process of solving problems in the financial sphere (as an example: when trading in the financial market).
\end{abstract}

Keywords: behavioural finance; theory of mind, financial decision making, optogenetics.

JEL Classification: D87.

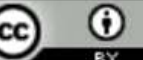

Cite as: Njegovanović, A. (2020). Mind Theory and the Role of Financial Decision and Process Role of Optogenetics. Financial Markets, Institutions and Risks, 4(1), 40-50. http://doi.org/10.21272/fmir.4(1).40$\underline{50.2020 .}$.

(C) The Author, 2020. This article is published with open access at Sumy State University.

\section{Extended Introduction}

Investigating the interaction of financial decision-making according to consistent theoretical analysis; from the introduction of the Theory of Mind (ToM) as the ability to recognize the characteristics of a mental state (thoughts, perceptions, desires, intentions, feelings-concepts have internal mentalistic and / or experiential content) and how mental states can affect behavior, why somebody works in a certain way or how to predict one's actions (Kloo et al., 2010), including the process role of optogenetics in financial decision making.

Defining the theory of mind according to Premack and Woodruff, 1978, emphasize the ability to merge mental states with others to make conclusions about their behavior. However, the present definition of the theory of mind points to the conceptualization of the theory of mind development that is also the subject of discussion among psychologists (Astington, 2006). We also come to a modular or domain-specific view of theoretical mind (Frith \& Frith, 1999; Saxe \& Powell, 2006).

From Socrates and Plato to the limited intellectual framework of the philosophy of human mind research ultimately, we come to mind in biological terms as a set of brain-driven processes. It is a complex computer device that constructs our perception of the outside world, improves our attention and controls our procedures. 
This philosophical shift from the explicit recognition of understanding of the human mind in biological terms is faced by scientists of the twenty-first century.

In the philosophical discussion there is a question of how mind and consciousness come from our matter, or more specifically, from the physical neurological processes in our brain. When we talk or think of the mind, it is natural to assume that it is directly related to our brains and our conscious thinking, including other cognitive functions. Even if direct experience and observation do not exist direct evidence / traces that could lead us to understanding the mind. We believe that mind is a phenomenon that is deeply associated with our brain activity.

The role played by the mind (when we observe and modulate our own emotional states) is in essence an active and physically effective process in which mental activity affects brain activity in a manner consistent with the laws of physics. The culturally relevant way of shaping this change suggests that modern physics encourages "psychhodynamics" with rigorous neurophysiological efficacy (mind and brain connectivity also supports clinical practice).

Decision Making / Financial Decision Making is a multiple process involving various phases of cognitive operations (conducted by Caitlin A. Orsini, Caesar M. Hernandez, Sarthak Singhal, Kyle B. Kelly, 3Charles J. Frazier, Jennifer L. Bizon, and Barry Setlow, Neuroscience, 2017). Bazolateral amygdala ("Some works have shown that the basolateral amygdala (BLA) is the key substrate for decision-making that includes the risk of punishment; however, it is not clear how BLA recruits at different stages of the decision-making process) is a substantive decision-making that includes the risk of punishment which optogenetics are used to inhibit basolateral amygdals for risk decision making. Decision-making is interrelated to the brain structures within the mesocorticolymbial circle (Orsini et al., 2015b). Within this circle is the basolateral amygdaladeciding on benefits and costs, is involved in decision-making involving the risk of explicit punishment (Orsini et al., 2015a).

Investigations using optogenetics to inhibit BLA during the specific phase of tasks in the risk decision making model (risk decision making) are experiments on rats that select a small, "safe" reward and a large reward followed by different probabilities of murder. It is interesting to monitor the process that "Long-Evans rats have received intra-BLA microinjection viral vectors carrying either halorhodopsin (eNpHR3.0-mCherry) or mCherry (control) followed by optical fiber implants and were trained in a risk task decision-making. Laser deliveries during the assignment occurred during intertrial intervals, reflections or phase outcomes, the latter being divided into three possible outcomes (small, safe, large, unpunished, large, fined). Inhibition of BLA selectively during the reflection phase reduced the choice of a large, risky outcome (reduced risk of choice). "By contrast, BLA inhibition selectively during delivery of a large, punitive outcome increases the risk of choice. Inhibition did not have any effect during the other phases, nor did the laser dose affect the effect of the control rats. Collectively, these data suggest that BLA can either prevent or promote the choice of risk options, depending on the decision making phase in which it is active. "

Decision-making is mediated by interrelated brain structures within the mesocorticolymbial circle (Orsini et al., 2015b). One such structure within this circle that has received considerable attention in deciding on costs / benefits is BLA (Winstanley and Floresco, 2016). Using well-validated rodent models for decision-making based on risk assessment, previous works have shown that lesions or pharmacological inactivation of BLA result in adverse selection (Winstanley et al., 2004; Ghods-Sharifi et al., 2009; Zeeb and Winstanley, 2011; Hosking et al., 2014; Tremblay et al., 2014). This is in line with neuroimaging data showing that the amygdala activates during risk assessment (De Martino et al., 2006, Roiser et al., 2009) and is hypoactive to people with impaired risk decision-making (Crowley et al., 2010). Gowin et al., 2013). More recently, BLA is involved in decision-making involving the risk of explicit punishment (Orsini et al., 2015a). In well-trained rats, BLA lesions increased the choice of a major reward associated with the risk of torture. These data suggest that BLA is critical for integrating information related to reward and punishment to guide optimal behavior. It is important, however, that it is unclear how and at what point of the decision-making process this integration is coming.

Neuroscientific research at MIT (Alexander Friedman et al., Cella, May 2015) identified neural circuits related to decision-making in conflict situations. Namely, understanding the decision-making process leads us to understand the role of striosomy (Ann Graybiel, et al., 2015). Deciding on costs and benefits leads to anxiety that understands both the quality of decision making or the wrong decision and is important for anxiety disorders. By using optogenetics, laboratory research by researchers has enabled inclusion or exclusion of 
cortical intestines in the striosom by detecting a circular linking striosum cortex that has a causal role in decision-making in avoiding access (Paul Glimcher, neuroeconomic father, physiology and neuroscience professor at the University of New York, new technology, optogenetics, opens the possibility of studying striato function in other types of decision-making). It is necessary to emphasize that striatum, especially striosomes, can absorb sensory and emotional information coming from the cortex and integrating them into decision-making mode.

In order to achieve the right choices, the costs and benefits of potential worthwhile outcomes must be taken into account, a process known to include nucleus accumbens (NAc) and its dopaminergic intake. However, the unknown is: if dopamine dynamically follows changes in the expected rewarding value of "online" as behavioral preferences change, if it is causally related to certain value components such as rewards and / or delays in reinforcement.

Behavior to get the desired prizes requires a complex estimate by comparing the costs of action-such as effort, delay to strength, and risk- to the benefit of the outcomes. These factors differ independently, requiring the calculation of subjective tolerance at various cost of behavior in relation to the advantage of the awards provided. Integral in this decision-making process is a neural circuit that includes the core accumbens (NAc) and its dopaminergic input (Fields HL, Hjelmstad GO, Margolis EB, Nicola SM, Day JJ, Roitman MF, Wightman RM, Carelli RM). Dopamine neurons encode reward predictions, showing increased activation on signs that reliably predict delivery (Pan WX, Schmidt R, Wickens JR, Hyland BI, Roesch MR, Calu DJ, Schoenbaum G), is reflected in the release of dopamine in NAc (Day JJ , Roitman MF, Wightman RM, Carelli RM., Sugam JA, Day JJ, Wightman RM, Carelli RM.). Mesolymbial dopamine is also included in the cost and benefit calculations needed to make value-based decisions. The role of activation of dopamine neurons follows the behavioral choices associated with the effort, delay, risk and probability of rewarding (Roesch MR, Calu DJ, Schoenbaum G, Fiorillo CD, Tobler PN, Schultz W. Fiorillo CD), and these signals reflect in phase release of dopamine in NAc (Day JJ, Roitman MF, Wightman RM, Carelli RM, Sugam JA, Day JJ, Wightman RM, Carelli RM). Perturbations of mesolimbic dopamine circuits, including NAc, lead to disadvantaged decision-making so that animals can not adequately adjust behavior as the reward value changes (Cardinal RN, Pennicott DR, Sugapathala SL, Robbins TW, Everitt BJ, Stopper CM, Khayambashi $\mathrm{S}$, Floresco SB.). Thus, the mesolymphic dopamine system not only encodes the prediction of reward values, but is also necessary for a dynamic cost estimate and behavioral adjustment to increase the amount of resources.

Financial decision-making involves two sources from which funds can be raised: using the company's own money (equity, retained earnings) or external borrowing in the form of bonds, a loan. The goal of a financial decision is to maintain an optimal capital structure, an appropriate mix of debt and equity to ensure a compromise between risk and invested return to shareholders. Decision-making links several areas of scientific research, including psychology, business management, economics (Bertrand, Mullainathan and Shafir, 2006); Neurosurgical decision-making processes focus on the importance of economic and financial decisions through the role of emotions in finances, psychological / neuropsychological factors that are present in financial markets, thus affecting financial / economic decisions.

Neuroscientists in the Blue Brain project using algebraic topology have been watching the brain in a new way by detecting neurons. Each group of neurons, by their size, forms their own high-dimensional geometric object. "We found a world that we never imagined," says researcher Henry M. Markram of the EPFL Institute in Switzerland. "There are tens of millions of these items even in the small" speck "of the brain, through seven dimensions. In some networks we have structures of up to eleven dimensions."

"Our brain is not an" independent "information processing body: it acts as a central part of our integral nervous system with recurring exchange of information with the entire organism and the cosmos. In this study, the brain is designed to be embedded in a holographic structural field that interacts with resonant sensitive structures in different cell types in our body. "(NeuroQuantology, September 2017, Journal of Neuroscience and Quantum Physics, released revolutionary work that could accelerate science of understanding of consciousness).

Optogenetics (a biological technique involving the use of light for cell control in living tissue, typically neurons, which are genetically modified for the expression of light sensitive ion channels, Wikipedia) allows researchers to control how the neuronal cells communicate (Oxford Living Dictionaries), a combination of 
genetics and optics control well-defined events within specific live tissue cells. Thus "Optogenetics is a technique that involves the use of light to manipulate cells with high temporal and spatial precision, in vitro or in vivo. By allowing selective targeting of individual cell types and turning them off and off their activity over biologically relevant time periods of milliseconds, optogenetics provide a certain level of specificity and control far beyond what can be achieved by the use of drugs or lesions. "(A comprehensive review of optogenetics, Louisa Lyon, Cambridge University, UK).

Optogenetics is a set of tools that enables us to turn on or off the electrical activity of neurons by the light impulse. Activating neurons or a set of neurons can see how this contributes to behavior or pathology, while disabling neurons can be understood for what is needed. Optogenetic tools can help understand the brain through two distinct areas of benefit: understanding the brain, which has humanistic and philosophical implications. For example, a group in Caltech used optical fiber along with optogenic tools in the deep part of the brain, making it susceptible to light. When they light up this area, the animals became aggressive. If we can understand the neuronal grounds of violence or aggression, it could do much to explain the aspirations of human behavior, and perhaps we could deal with some of these mysteries and clinical applications, if we can use light to more actively activate a set of neurons, maybe we could treat patients suffering from Parkinson's disease, chronic pain, deafness or other conditions.

\section{Review of Neurobiology of Mind Theory}

In the constructivist framework, mind theory is integrated into a structure that includes general capabilities such as executive function and language (Milligan, Astington and Dack, 2007; Apperly, Samson, Chiavarino, Bickerton and Humphreys, 2007). The development of the theory of mind is largely influenced by the development of associated cognitive abilities and is more variable in its expression and underlying structure. Advocates of this approach do not believe that the theory of understanding the mind requires specific development of the mechanism for a particular domain (Stone \& Gerrans, 2006).

The development and progression of neuroscience is the solution of neurological mapping of social cognitive functions. Modular Account Holders of Mind Mind believe that the specific-specific mechanism is responsible for the attribution and understanding of mental states. The evidence for support comes from research that studies the false understanding of beliefs - the understanding of the mental states of others can oppose the current state of reality - typical and atypical populations (Leslie \& Thaiss, 1992 Saxe \& Baron-Cohen, 2006). Research has shown that individuals may have a unique disadvantage in understanding false beliefs while still showing a normal range of action on similar tasks that do not require meta-representation of mental states (Leslie \& Thaiss, 1992). Competitors believe that structures associated with mind-understanding theory need to show unique patterns of activation during the processing of mental representations and should be less active during the processing of non-mental representations (Saxe \& Baron-Cohen, 2006).

Brain imaging enabled direct testing of the modular account and brain region identification associated with the theory of understanding the mind. These regions include right and left temporo-parietal joint and back cingulus (Frith \& Frith, 1999; Saxe \& Powell, 2006; Sabbagh \& Taylor, 2000). The most consistent were the selective activation of the true temporo-parietal bond during the processing of false beliefs (Perner, Aichhorn, Kronbichler, Staffen \& Laudurner, 2006, Saxe \& Powell, 2006). Studies have shown that activation of the right temporo-parietal node could be selectively linked to the processing of the mental state perspective, but not with the more general types of meta-representation. Research carried out by Pernera et al. (2006) by fMRI. Scenarios were designed so that the participants in the experiment should consider the mental state of others when they respond to the question of false opinion (a tourist who mistakenly believes in the sights site after receiving false instructions), but not with the interpretation of a false sign (a road sign that shows a wrong direction) or false photographs (a dated picture of a scene that has since changed). Researchers could differentiate neural activation patterns that were uniquely associated with meta-representation of mental and non-mental states. The results (Pernara et al.)

Found that activation in the left temporo-parietal joint (TPJ-L) did not differ between the processing of false beliefs and false signs, activation in the right temporo-parietal compound (TPJ-R) false beliefs than during the processing of the other two scenarios. The authors have concluded that TPJ-R can be uniquely associated with meta-representation of mental states and can therefore be a good candidate for the theory of "module" mind. Similar findings were obtained from Saxe and Powell (2006), which found that TPJ-R was actively activated when participants were asked to read the description of the protagonists of thought or belief, but not when they read about the protagonist's appearance or subjective physical feelings (hunger) . 
I am trying to clarify whether the ability to understand mental states depends on (1) the development of highly specialized neural structures, or (2) the formation of pathways between structures that are related to the general functions of the area. Evidence suggests strong support for the existence of structures specializing in solving the theory of understanding the mind (Saxe \& Powell, 2006; Perner et al., 2006). Although some studies also show that understanding of a mental state is associated with an integrated set of general area structures (medial prefrontal cortex), evidence supporting a specialized role of the right temporo-parietal node can not be discarded. The question is whether the specialization of neural structures in the brain of adults provides unambiguous support for the modular development of the theory of mind in young children. Based on the recent Neuronal Development Model (Johnson, 2000; Karmiloff-Smith, 2007), it can also explain the development of structural-specific structures by constructivist perspective.

Superior temporal sulcus (STS) is based on ToM, although the role of STS is not entirely clear. Research has revealed that the true STS is linked to understanding the meaning of the story of engaging people (Gallagher $\&$ Frith, 2003). Some research has found the activation in STS associated with the attribution of intent to move geometric shapes, taking the first perspective and explaining the behavior of others by recognizing their mental state (Gallagher and Frith, 2003). A large number of neuro-imaging studies link the perception of biological motion with activation in SPS. Studies have shown that selective participation in facial emotions increases activation in the right STS compared to simple presence on the face (Gallagher and Frith, 2003). Based on these studies, Gallagher and Frith (2003) have indicated that STS is involved in detecting mediator behavior and analyzing the goals and outcomes of such behavior. Aymgdala can also contribute to the capabilities of ToM. Functional painting in the Social Cognition Study found the activation of amygdala in response to unreliable faces, regardless of whether the volunteer clearly considered reliability. By contrast, STS is only active during explicit estimates of unreliability. Gallagher and Frith indicate that automatically responding to a socially prominent stimulus amygdale can be important to the development of ToM.

Although the existence of a highly specialized structure can provide specific support for modular assessments of the theory of mind development, recent models of neuronal development, however, cause suspicion for such a conclusion. Alternatively, the model of theory of mind development that is based on the principle of probabilistic epigene can offer more detailed explanations rather than a description of current neurological evidence. This model can take into account possible deviations in the functional localization of the mental state, also this model can take into account the simultaneous employment of highly specialized and general pathways in areas of mental representation.

\section{The Scientific Theory of Mind and Human Brain/Making Decisions}

The British philosopher and psychologist Place wrote in his 1954 work " Is brain consciousness conscious?" this statement: "The standpoint of the existence of a separate class of events, mental events, which can not be described in terms of concepts applied in physical sciences, no longer dominates the universal and unquenchable acceptance of the philosopher and psychologist he once did." Summarized, mind theory and The brain assumes that the mind is simply a part of the physical body. Our minds and brains have the ability to see their inner causes, thoughts and intentions behind physical actions. The Theory of Mind (ToM) is a tool for understanding and interpreting the external actions of others.

Neuroscience provides us with the foundation for cognitive neuroscience. What are the ToM Neural Substrate? Are there selectively recruited different brain regions for ToM (such as exist for vision, auditory and engine control)? If so, what are (and are not) those brain regions? Are there different cognitive components of ToM? People can think of other people as an infinite series of beliefs and desires, from trivial to exalted, from known to exotic, from simple to extremely complex (complex decision on financial investment). Many different brain regions are involved when people do the Theory of Mind tasks for a variety of reasons. Differences between the regions of the brain can be detected through an imaginary meta-experiment.

Mind theory? We experience our own thoughts, but not the thoughts of others - since we can not get into the heads of other people, how do we know what's inside? How does our brain overcome the gap between our minds? Understanding the thoughts of other minds could be used by "simulation" (Goldman, 2006). Simulations help other people understand because they are similar to us: they perform similar movements, experience similar sensations, and make similar decisions using a body and mind similar to their own. As a result, we could use our own mind (and body) as an analogy to the mind of another person. We can re-create a copy of their works and feelings and recapitulate their own experiences in order to understand their own. 
Can this be a recognizable function of the brain area of ToM to build a suitable and useful simulation of other people's thoughts? People simulate the actions they observe by activating appropriate motor displays in their own brain and body. When someone observes someone, the observer can not help but activate the same muscles and engine plans for that action (Fadiga, Craighero and Olivier, 2005). As a result, observation of the actions hinders the execution of the action, and the execution of the action interferes with the observation activities (Kilner, Paulignan \& Blakemore, 2003; Zwickel, Grosjean \& Prinz, 2010a, 2010b). Even when the activities of another person are invisible, knowledge of someone else's incompatible action can cause interference. In the study, Sebanz and his colleagues have shown that disturbances from thinking of another's actions can be compared with competition from their own procedures (Atmaca, Sebanz, \& Knoblich, 2011; Sebanz, Knoblich \& Prinz, 2003). If one person sees more or less than the other person, then compete with their own verbal report position (Samson, Apperly, Braithwaite, Andrews \& Scott, 2010). These results show that observation and understanding of the action and experience of another person compete for the same cognitive and neural resources as those used for their own procedures and experiences.

Neural evidence converges to the same simulation story. Activity in the parietal cortex that looks to someone else to perform with a simple hand is removed if the participant previously made the same hand. This response suggests that the representation of one's own action may be partially "recycled" during the observations of others (Chong, Cunnington, Williams, Kanwisher and Mattingley, 2008). Watching the movement manually leads to preparatory activities in your own motor cortex and mouse hand; this activity can be seen if it is pushed artificially across the threshold by TMS pulse (Stürmer, Siggelkow, Dengler \& Leuthold, 2000). These activations are modulated by experience: the more experienced observers actually carry out a particular action, the more their motor cortex is activated while watching others performing the same activity. In one example, the ballet dancer's motor cortex showed greater activity when dancers watched sex-specific movements that had more experience in performing (Calvo-Merino, Glaser, Grezes, Passingham and Haggard, 2005 Casile \& Giese, 2006, Hamilton and Grafton, 2006). For example, male dancers showed more motor activity than dancers when observing the movements usually performed by male dancers, although male and female dancers have the same experience of observing these movements. A similar form is related to the observation of physical sensations in another person, especially physical ailment. A common group of brain regions is recruited when people feel their pain and when they see someone else in pain. Pain experience leads to brain activity in the "pain matrix", including cingular cortex regions, secondary sensory cortex and bilateral insulans. When observers testify to other people in bodily pain, some of the same brain regions are activated (Botvinick et al., 2005; Jackson, Rainville \& Decety, 2006; Singer \& Lamm, 2009; Singer et al., 2004). Activity in some of these areas correlates with pain intensity, whether experienced (Peyron, Laurent, \& Garcia-Larrea, 2000) or attributed (Saarela et al., 2007).

Christoph Engel and Wolf Singer (MIT Press, 2016) point to research on conscious decision-making control that leads to innovative solutions but also the determinants of conscious information processing. "Conscious decision-makers are subject to hundreds of prejudices, but measured according to the rational election theory standards, they are poorly performing. If they give up conscious control, in the right tasks, people are performing surprisingly better. Report by Strüngmann Forum (2008), which explored the human ability to make decisions: conscious and unconscious control; intentionally and intuitively; explicit and implicit; processing information serially and in parallel; with a general purpose device or with task-specific neural subsystems. The analysis has been conducted on four levels - neuronal, psychological, evolutionary and institutional - resulting in differing from what is expected under the standard theory of rational choice and deviating even more from an alternative view of the behavior of institutions. It is also necessary to look at The Ernst Strungmann Forum dedicated to the promotion of interdisciplinary communication and research. It facilitates the expansion of knowledge by providing experts with a creative environment to scrutinize highpriority problems from multiple perspectives. The insights and future research directions that emerge are disseminated in the Strüngmann Forum Reports.

\section{Neural Sytems and Theory of Mind}

Social-cognitive neuroscience of research contributes to the understanding of neural systems that are the basis of mind theory. In research and analysis, we encounter problems related to mind theory such as brain imaging research that require better differentiation rather than just data collection. The estimate of modularity (Leslie et al.,) Explicitly includes the selection procedure. Challenges are manifested through mechanisms for acquiring a theory of mind that is difficult to articulate so that it can be tested at a neuronal level. Conceptual change, the central mechanism in theoretical theory, is a rather abstract construct that could have many forms 
both at the behaviour level and at the neuronal level (Gopnik and Wellman, 2012, to try to translate theory into a more precise computer format). It is difficult to define a simulation, as there are several ways to approximate the content of another mind. There are many questions that remain regarding simulations, such as the measure of automatic / implicit or conscious / explicit. Such differences have implications for simulation measurement. Given the modularity theory, progress in defining and quantifying neural selectivity (Saxe, 2010, Saxe et al., 2009) provides an example of how complex neural processes can be measured and used to test the theory. If we could quantitatively quantify conceptual change or simulation in terms of expected differences in brain activation or increased selectivity of neuronal structures, we could better obtain evidence that would support or reject relevant theories.

How to conceive the maturity of neural networks involved in the processing of ToM? The brain regions involved in thinking about ToM are still developing in adolescence as well as the performance of ToM in Behavior (Dumontheil et al., 2010), so it is important to clarify which criteria are used to take neural treatment as "mature" (Pfeifer and Allen, 2012). For example, we could define maturity in terms of neuronal function that supports successful behavioral behaviors. So even though 5-year-olds may not have fully developed brain regions in the ToM network, neural processes that allow them to pass simple fake beliefs can be considered 'mature'. Alternatively, maturity can be defined by the speed or efficiency of Neuronal systems that support $\mathrm{ToM}$, in which case neural systems based on false understanding of beliefs would not be considered mature until much later.

The ability to conclude the intentions of other mediators, called Theory of Mind (ToM), gives strong benefits to individuals in social situations. Theory of mind may also be inadequate when people interact with complex modern institutions such as financial markets. Tested participants who invested in the experimental bubble market, a situation where property prices are significantly higher than the baseline value. The experiment describes the mechanism by which social signals are calculated in the dorsomedial prefrontal cortex that affect the value of the ventromedial prefrontal cortex, thereby increasing the individual's tendency to "drive" financial bubbles and lose money. These regions calculate a financial measure that signals variations in the direction of the flow rate, which leads to a conclusion on the intentions of other traders. The obtained results indicated that incorporating conclusions on the intentions of others in making valuations on a complex financial market could lead to the formation of market bubbles.

The academic community points out that finances are based on the assumption that individuals are acting rationally, considering all available information in the decision-making process, and the expected utility theory is the model of choice under security conditions. Actually, when it comes to financial decisions, investors are not always as rational as we think. A new area of finance, called finance behaviors, examines why some merchants achieve good success while others gamble with wealth. Behaviors include sociology and psychology, presenting a new approach to financial markets, in response to difficulties with classical finance theories. Although standard financial theory assumes that competitive markets are unreal, it is not uncommon for people to market their intentions. Financial commentators often say, anthropomorphically, that "pancreatic markets" or "markets lose their trust". Assigning an Intent or agency is a natural way for people to model and interpret complex behavior (as in the case of "simple" societies in which people think gods are managing natural processes like time). People live in social environments and therefore usually benefit from the capabilities of ToM that enable them to predict others' intentions and take preventative action (Fehr and Camerer, 2007, Frith and Frith, 1999, Gallagher and Frith, 2003, Sanfey, 2007) (dmPFC) (Amodio and Frith, 2006; Frith and Frith, 2006).

By applying the independent task ToM (Baron Cohen et al., 2001), it shows an increase in activity isolated in the bubble market that correlates with individual ability in ToM. The commercial activity on six real-world experimental markets -included in previous behavioral studies: Porter and Smith, 2003- was repeated during a two-day scanning schedule, Each market traded on three experimental markets, each market divided into fifteen trading periods, and during each trading period, the scanned participants watched a quick visual display of the bidding price and the bidding offer that actually contributed to the participants in the original behavioral experiments). The functional link between dmPFC ( dorsomedial prefrontal cortex ) and vmPFC ( ventromedial prefrontal cortex ) was increased during the bubble market. The obtained data indicated that during the financial bubbles participants took into account the intention of other players in the market (or markets as a whole) to update their value estimation, this effect was mediated by interaction between dmPFC and vmPFC. Previous studies also stressed the role of dmPFC in shaping the value calculation by showing 
that social signals change the way values are updated through learning (Behrens et al., 2008; Hampton et al., 2008; Behrens et al., 2009; Suzuki et al. sur., 2012). Activity in dmPFC correlates with the likelihood that players playing a "play-or-avoid / deny" strategic game learn the value of action using a model that takes into account the intentions of other players in the game (Hampton et al., 2008). Nicolla et al. (Nicolle et al., 2012) suggested that dmPFC is not specifically involved in mentalization but has a more general role in representing the values of works that have been modeled but not executed while vmPFC is involved in representing only those values that are relevant to the decision of the decision-maker. According to this framework, the complementary interpretation of our results is that activity in $\mathrm{dmPFC}$ reflects the value calculation associated with modeled alternative choices (eg, purchase at different prices from core value) that are especially important for merchants in the bubble market when price is very variable.

One of the cognitive abilities separating human race from many other species is the theory of the mind that records the ability of an individual to attribute mental states to himself and to other individuals (Premack \& Woodruff, 1978). It is also necessary to emphasize the interaction of mind theory and artificial intelligence. Interaction of people with intelligent non-human mediators that affect the human attribution of mental states to machines. Many algorithms that use AI are not fully written by programmers, but instead rely on machine learning. The solutions created by the computer are black boxes with algorithms that are very complex for human insight. Therefore, Neil Rabinowitz, a DeepMind scientist from London and colleagues, created the theory of AI called "ToMnet" (artificial intelligence and computers, Stockholm, 2018- Neil Rabinowitz). ToMnet consists of three neural networks, each of the small computer elements and relationships that learn from experience, loosely like the human brain. The first network teaches the tendencies of other AIs based on their past actions. The other form makes the understanding of their present "beliefs". The third takes the exit from the other two networks and, depending on the situation, anticipates the following moves of AI. Josh Tenenbaum, a psychologist and computer scientist at the Massachusetts Institute of Technology in Cambridge, also worked on computer models of theory of mind ability based on a more abstract form of probabilistic thinking than neural networks.

\section{Instead Conclusion}

We are witnessing a dramatic increase in the amount of complexity that exists in the world. Global economy is a network of resource companies and interdependent. Our knowledge becomes deeper and more detailed at an accelerating speed. New sources of complexity increase the frequency and amplitude of positive and negative feedback loops. Our ability to think and make smart decisions erodes as our environment has become more complex and more difficult to accept our traditional tools. We note more than 200 cognitive shortcuts and prejudices that have evolved as tools and decision-making speeds are growing. Sometimes our brain is lying. We believe we are rational actors in the markets, but from time to time we find it very difficult to see the thinking about our thinking. And now in global uncertainties it is getting harder. We move to the theory of mind by reviewing the functional relationships of financial decision-making and optogenetics. We experience our own thoughts, but not the thoughts of others - since we can not get into the heads of other people, how do we know what's inside? How does our brain overcome the gap between our minds? Understanding the thoughts of other minds could be used by "simulation" (Goldman, 2006). Simulations help people understand because they are similar to us: they perform similar movements, experience similar sensations, and make similar decisions using a body and mind similar to their own. As a result, we could use our own mind (and body) as an analogy to the mind of another person. Why is knowledge of mind theory important and how do you connect with financial decision making? Theory of Mind (ToM) is the ability to recognize and characterize mental states - thoughts, perceptions, desires, intentions, feelings - towards oneself and others and how these mental states can affect behavior. It also leads to the understanding of others who have beliefs, thought processes and emotions completely separate from ours. Disability in ToM may occur in people with Asperger's syndrome, autism, schizophrenia, sociopathy and other mental disorders (Encyclopaedia of Psychology).

We have mechanisms by which social signals are calculated in the dorsomedial prefrontal cortex that affect the value of the ventromedial prefrontal cortex, thereby increasing the individual's tendency to "drive" financial bubbles and lose money. Often we can hear from financial commentators saying anthropomorphic that "pancake markets" or "markets lose confidence". Assigning intent is a natural way for people to model and interpret complex behavior (as in the case of "simple" societies in which people think gods are managing natural processes like time). People live in social environments and therefore usually benefit from the capabilities of ToM that enable them to predict others' intentions and take preventative action (Fehr and 
Camerer, 2007, Frith and Frith, 1999, Gallagher and Frith, 2003, Sanfey, 2007) (dmPFC ) (Amodio and Frith, 2006; Frith and Frith, 2006).

And et the end. Deciding at any level is a network of scientific branches that enable us to understand the complexity of financial decision-making and the inclusion of laws of thermodynamics / entropy. Researchers ((France and Canada, 2018) have analyzed the order of magnitude in our brain while we are aware of it when we did not do it, they did by modeling neuron networks, (experimental approach), Researchers found that brain participants showed greater entropy when they were fully aware. "We find a surprisingly simple result: normal states of alertness are characterized by the greatest number of possible configurations of interactions between brain networks, which represent the highest values of entropy. "Of course, these researches were conducted on a small number of participants in the experiment but gave us insights into the complexity of research and guidance involving science in solving problems that occur in trading in the financial market.

\section{References}

1. Gopink, H.M. Wellman. (2012). Reconstructing constructivism: causal models, Bayesian learning mechanisms and the theory theory, Psychological Bulletin, 138, 1085-1108. Available at: https://www.ncbi.nlm.nih. gov/pubmed/22582739

2. Apperly, I. A. Samson, D., C., Bickerton, W. L., \& Humpreys. G. W. (2007). Testing domain- specifity of a theory of mind deficit in brain-injred patients: Evidence for consistent performance on non-verbal,. ,realityonknowen" false belief photograph tasks. Cognition, 103, 300-321. Available at: https://www.ncbi.nlm.nih.gov/pubmed/16781700

3. Atmaca, S., Sebanz. N., \& Knoblich, G.(2011). The jojint flanker effect: Sharing tasks with real and imagined co-actors. Experimental Brain Research, 211 (3-4), 371-385. Available at: https://www.ncbi.nlm.nih.gov/pmc/articles/PMC3102196/

4. $\quad$ Baron-cohen S., Wheekwright S., Hill J., Raste Y., Plumb I. ( 2001). The 'Reading the Min din the Eyes' Test revised version: a study with normal adults with asperger syndrome or high-functioning autism. J.Child Psychol.Psychiatry, 42, 241-251. Available at: http://docs.autismresearchcentre.com/papers/ 2001_BCetal_adulteyes.pdf

5. Bechara, A., Damasio, H.( 2002). Decision-making and Addiction: I. Impaired activation of somatic state sin substance dependent individuals when pondering decisions with negative future concequnces. Neuropscyhologia 40: 1675-1689. 10.1016/50028-3932(02)00015-5.

6. Calvo-Merino, B., Glaser, D.E., Grezes, J., Passingham, R.E.,\& Haggard, P. (2005). Action observation and acquired motor skills: An fMRI study with expert dancers. Cerebral Cortex, 15(8), 1243-1249. Available at: https://www.ncbi.nlm.nih.gov/pubmed/15616133

7. $\quad$ Camerer, C.F., Weigelt, K. ( 1993). Convergence in experimental double auctions for stochastically lived assets. In: Friedman, D., Rust J., editors. The Double Auction Market: Theories, Institutions and Experimental Evaluations, Addision-Wesley; Redwood City, CA.

8. Cardinal, R.N., Pennicott, D.R., Sugapathala, S.L. Robbins, T.W., Everitt, B.J. (2001). Impulsive choice induced in rats by lesopns oft he nucleus accumbens core. Science, 292: 2499-2501. Available at: https://www.ncbi.nlm.nih.gov/pubmed/11375482

9. Casile, A., \& Giese, M.A. (2006). Nonvisual motor training influences biological motion perception. Current Biology, 16(1), 69-74. Available at: https://www.ncbi.nlm.nih.gov/pubmed/16401424

10. Chong, T.T., Cunnington, R., Williams, M.A., Kanwisher, N.,\& Mattinglev, J.B., (2008). Fmri adaption reveals mirror neuron sin human inferior parietal cortex. Current Biology, 18(20), 1576-1580. Available at: https://www.ncbi.nlm.nih.gov/pubmed/18948009

11. Crowley, T.J., Dalwani, M.S., Mikulich-Gilbertson, S.K., Du Y.P., Lejuez, C.W., Raymond KM, Banich MT (2010). Risky decisions and their consequences: neural processing by boys with Antisocial Substance Disorder. PLoSOne 5:e12835. 10.1371/Journal.pone. 0012825.

12. Dekkers, T.J., Popma, A., Agelink van Rentergem J.A., Bexkens A., Huizenga H.M. (2016). Risky decision making in Attention-Deficit/Hyperactivity Disorder: a meta-regression. Clin Psychol. Rev 45:1-1510. 10.1016/j.cpr.2016.03.001.

13. DeMartino B., Kumaran D., Seymor B., Dolan R.J. (2006). Frames, Biases, and rational decision-making in human brain. Science 313:684-687. 10.1126/science. 1128356.

14. Fadiga, L., Craighero, L., \& Oliver, E.( 2005). Human motor cortex excitability during the perception of others action. Current Opinion in Neurobiology, 15(2), 213-218. Available at: https://www.ncbi.nlm.nih.gov/ pubmed/15831405 
Financial Markets, Institutions and Risks, Volume 4, Issue 1, 2020 ISSN (online) - 2521-1242 ISSN (print) - 2521-1250

15. Fields H.L., Hjelmstad, G.O, Margolis, E.B., Nicola SM. (2017). Ventral tegmental area neuron sin learned appetive behavior and positive reinforcment. Annu Rev Neurosci, 30, 289-316. Available at: https://www.ncbi.nlm.nih.gov/pubmed/17376009

16. Ghods-Sharifi, S., Floresco, S.B. (2010). Differential effects on effort discounting induced by inactivations oft he nucleus accumbens core or shell. BehavBeurosc, 124.179-191. Available at: https://www.ncbi.nlm.nih.gov/pubmed/20364878

17. Hamilton, D., \& Sherman, S.( 1996). Perceiving persons and groups. Psychological Review, 103 (2), 336355. Available at: https://www.ncbi.nlm.nih.gov/pubmed/8637962

18. Hosking, J.G., Cooker, P.J., Winstanley, C.A. (2014). Disociable contributions of anterior cingulate cortey and basolateral amygdala on a rodent cost/benefit decision-making task of cognitive effort. Neuropsychopharmacology, 39,1558-1567. 10.1038/npp.2014.27.

19. Dumontheil et al., (2010). Online usage of theory of mind continues to develop in late adoloscence. Development Science, 13, 331-338. Available at: https://www.ncbi.nlm.nih.gov/pubmed/20136929

20. Jackson, P.L., Rainville, P., \& Decety, J. (2006). To what extent do we share the pain of others? Insight from the neural bases of pain emoathy. Pain, 125(1-2), 5-9. Available at: https://www.ncbi.nlm.nih.gov/ pubmed $/ 16997470$

21. J.H. Pfeifer, N. Allen, (2012). Arrested development? Reconsidering dual-systems models of brain function in adolescence and disorders. Trend sin Cognitive Sciences, 16, 322-329. Available at: https://www.ncbi.nlm.nih.gov/pubmed/22613872

22. Kaye, W.H., Wierenga CE, Bailer UF, Simmons AN, Bischoff-Grethe A. (2013). Nothing tastes as good as skiny feels: the neurobiology of anorexia nervosa. Trnds Neurosci, 36, 110-120. 10.1016/ j.tns. 2013.01.003.

23. Kilner, J.M., Paulignan, Y., \& Blakemore, S.J. (2003). An interference effect of observed biological movement on action. Current Biology, 13(6), 522-525. Available at: https://www.ncbi.nlm.nih.gov/pubmed/12646137

24. Najavits LM, Meyer T, Johnson KM, Korn D. (2011) Patholocical gambling and posttraumatic stress disorder: a study oft he co-morbidity versus each alone. J.Gambl Stud, 27, 663-683. 101007/s10899-010-9230-0.

25. Orsini, C.A., Trotta, R.T., Bizon, J.L., Setlow, B. (2015a). Dissociable roles for the basolateral and orbitofrontal cortex in decision making unde risk of punishment. J Neurosci, 35,1368-1379. 10.1523/Neurosci.3586-14.2015.

26. Pan WX, Schmidt R, Wickens JR, Hayland BI. (2005). Dopamine cells respond to predicted events during classical conditioning: Evidence for eligibility traces in the reward -leraning network, Journal of Neuroscience. 25:6235-6242.

27. Saxe et al.,( 2009). Brain regions for perceiving and reasoning about other people int he school- aged children. Child Development , 80, 1197-1209. Available at: https://srcd.onlinelibrary.wiley.com/doi/ 10.1111/j.1467-8624.2009.01325.x

28. R. Saxe. (2010). The right temporo-parietal junction: a specific brain region of thinking about thoughts,((2010): A. Leslie, T. German ( Eds ). Handbook of Theory of Mind. Available at: http://saxelab.mit.edu/ publications/right-temporo-parietal-junction-specific-brain-region-thinking-about-thoughts

29. Roiser JP, deMartino B, Tan GC, Kumran D, Seymour B, Wood NW, Dolan RJ. (2009). A geneticaly mediated bias in decision making driven by failure of amygdala control. Neurosci 29:5985-5991. 101523/Nurosci.0407-09.2009.

30. Samson, D., Apperly, I. A., Braithwaite, J., Andrews, B., \& Scott, S. (2010). Seeing it their way: Evidence for rapid and involuntary computation of what other people, Journal of Experimental Psychology: Human Perception and Performance, 36 (5), 1255-1266.

31. Saarela, M.V., Hlushchuk, Y., Williams, A. C., Schurmann, M., Kaslo, E., \& Hari,R. (2007). The compassionate brain: Humans detect intensity of pain from anothers face. Cerebral Cortex, 17(1).

32. Scheinder, S., Peters, J., Bromberg, U., Brassen, S., Miedl, S.F., Banachewski, T., Barker, G.J., Conrod, P., Flor, H., Garavan. H., Heinz, A., Ittermann, B., Lathrop M, Looth E, Mann K, Martinont JL, Nees F, Paus T, Rietschel M., Robbins T.W., et. al. (2012). Risk Taking and the adolescent reward system: a potencional common link to substance abouse. J. Psychiatry 169:39-46.

33. Singer, T., \& Lamm, C. (2009). The social neuroscience of empathy. Annals of the New York Academy of Science, 1156, 81-96. Available at: https://www.ncbi.nlm.nih.gov/pubmed/19338504

34. Singer, T., Seymour, B., ODorothy, J., Kaube, H., Dolan, R. J., \& Frith, C. D. (2004). Empathy for pain involves the affective but not sensory components of pain. Science, 303 (5661),1157-1162. Available at: https://www.ncbi.nlm.nih.gov/pubmed/14976305 
ISSN (online) - 2521-1242 ISSN (print) - 2521-1250

35. Stopper, C.M., Tse, M.T., Montes, S.R., Wiedman, C.R., Floresco, S.B. (2014). Overriding phasic signals redirects action selection during risk/reward decision making. Neuron. Available at: https://www.ncbi.nlm.nih.gov/pubmed/25220811

36. Sugam, J.A, Day, J.J., Wightman, R.M., Crelli, R.M., Crowley, T.J., Dalwani, M.S., Mikulich-Gilbertosn, S.K., Du, Y.P., Lejuez, C.W., Raymond, K.M., Banich, M.T. (2010). Risky decision and their consequences: neural processing by boys with Antisocial Substance. Disorder. PLos. Available at: https://journals.plos.org/plosone/ article? $\mathrm{id}=10.1371$ /journal.pone.0012835

37. Tremblay, M., Cocker, P.J., Hosking, J.G., Zeeb, F.D., Rogers, R.D., Winstanley, C.A. (2014). Disociable effects of basolateral amygdala lessions on decision amking biases in rats when loss or gain is emphasized. Cogn Affect Behav Neurosci 14:1184-1195. Available at: https://www.ncbi.nlm.nih.gov/pubmed/24668615

38. Winstanley, C.A., Theobald, D.E., Cardinal, R.N., Robbins, T.W. (2004). Contrasting roles of basolateral amygdala and orbitofrontal cortex in implusive choice. J. Neurosci 24:4718-4722. Available at: https://www.ncbi.nlm.nih.gov/pubmed/15152031

39. Winstanly, C.A, Floresco, S.B., (2016). Deciphering decision making: variation in animal models of effortand uncertinaty-based choice reveals distinct neural circuitries underlying core cognitive processes. J. Neurosci 36:12069-12079. Available at: https://www.ncbi.nlm.nih.gov/pubmed/27903717

40. Zeeb, F.D., Winstanley, C.A. (2011). Lesions of the basolateral amygdala and orbitofrontal cortex differentially affect acquistion and performance of a rodent gambling task. J. Neurosci 31:2197-2204. Available at: https://www.ncbi.nlm.nih.gov/pubmed/21307256 